\title{
A Glass Painting by Raphael Sanzivs (1483-1520) Revealed by its Partially Hidden Signatures on the Characters' Anatomy
}

\author{
Deivis de Campos, ${ }^{1,2,3}$ Danielle Coutinho Rodrigues, ${ }^{1}$ Tais Malysz, ${ }^{4}$ Adriana Augusti,,${ }^{5,6}$ Luciano Buso ${ }^{7}$ \\ 'Departamento de Ciências Básicas da Saúde, Universidade Federal de Ciências da Saúde de Porto Alegre, Porto Alegre, RS, Brazil \\ 2Departamento de Ciências da Vida, Universidade de Santa Cruz do Sul, Santa Cruz do Sul, RS, Brazil \\ 3Programa de Pós-Graduação em Promoção da Saúde, Universidade de Santa Cruz do Sul, Santa Cruz do Sul, RS, Brazil \\ ${ }^{4}$ Departamento de Ciências Morfológicas, Instituto de Ciências Básicas da Saúde, Universidade Federal do Rio Grande do Sul, Porto Alegre, \\ RS, Brazil \\ ${ }^{5} \mathrm{Già} \mathrm{ispettore} \mathrm{dell'arte,} \mathrm{Ministero} \mathrm{dei} \mathrm{Beni} \mathrm{e} \mathrm{delle} \mathrm{Attività} \mathrm{Culturali} \mathrm{e} \mathrm{del} \mathrm{Turismo,} \mathrm{Venice,} \mathrm{Italy}$ \\ ${ }^{6}$ Già direttore della Galleria Giorgio Franchetti alla Ca' d'Oro, Venice, Italy \\ ${ }^{7}$ Studioso e ricercatore scientifico nel campo dell'arte, San Vito di Altivole, 31030, Treviso, Italy
}

Disclose and conflicts of interest: none to be declared by all authors

\section{ABSTRACT}

Introduction: The study of anatomy, besides being important to the medicine, has traditionally always been present in the daily life of many artists since of the antiquity. Thus, the specialized literature has described that the notorious Renaissance artist, Raphael Sanzivs Vrbinas (1483-1520) is among the greatest anatomist-artists of his time. In this context, this manuscript shows in detail that Raphael Sanzivs may have partially hidden his signatures/initials ['SANZIVS', 'RAPHAEL', 'RVS', 'RV', 'RS', 'RA'] in the anatomy of the characters of a painting on glass dated 1513 [belonging to a private collection], on which is represented St. Joseph and the Infant Jesus.

Materials and Methods: All the analysis made on this painting on glass, were performed by highly experienced specialists on artworks of the Renaissance period.

Results: These partially hidden signatures of Raphael Sanzivs, besides evincing the artist's abilities related to the painting techniques and his interest regarding the human anatomy, may also be useful for further studies that aim the verification of Raphael Sanzivs' authorship on the paintings that haven't yet been attributed to the artist.

Conclusion: The present manuscript shall be important for professionals in the medical-artistic field and those who keep some interest in the history of anatomy.

Keywords: Raphael Sanzivs; Hidden signatures; Human anatomy; History; Painting on glass.

\section{Introduction}

The specialized literature ${ }^{1-3}$ has described that the notorious Renaissance artist, Raphael Sanzivs Vrbinas (1483-1520) was a great scholar of human anatomy. In this context, along with Leonardo da Vinci (1452-1519) and Michelangelo Buonarroti (1475-1564), Raphael Sanzivs is among the greatest anatomist-artists of his time. ${ }^{2-4}$

During the Italian Renaissance, the study of the human anatomy became a need among the great artists, because from this learning on, certainly, all the representations of the human body in their paintings would be much closer to reality. ${ }^{4-7}$ Indeed, at that time, artists considered it a necessity to become anatomists, in their attempt to produce a more lifelike, sculptural portrayal of the human body. According to the new Renaissance wave, art should not just be a copy of the classic nudes of antiquity but a bearer of a new spirit for which anatomical dissections were crucial to better reproduce the body, its movements and functions, as well as its supporting structures in art.8,9

Additionally, some paintings of many Italian
Renaissance artists, including those from Raphael Sanzivs, are steemed not only for the beautiful representations of the human body, but also for presenting partially hidden secret codes and faces/ signatures. ${ }^{4,10}$ In this context, this manuscript shows in detail that one of the greatest anatomist-artists from the Italian Renaissance, Raphael Sanzivs, ${ }^{2-4}$ may have partially hidden his signatures/initials in the anatomy of the characters of a painting on glass dated 1513.

\section{Materials and Methods}

\section{Analysis}

Since 2008, a Raphael Sanzivs' painting on glass, on which is represented St. Joseph and the Infant Jesus [belonging to a private collection], has come to be thoroughly studied in an artwork restoration laboratory [Italy] (Figure 1). On the first description/ publication about the glass painting, it was postulated that it could have been made in 1508. ${ }^{11}$ Nevertheless, this manuscript demonstrates through recent analysis that it may have been painted in 1513. All the analysis [technical, historical and iconographic] made on 
this painting on glass, were performed by highly experienced specialists on artworks of the Renaissance period.

\section{Technical analysis}

The painting on glass was made with oil paint or tempera, and all the lines on the canvas are immaculate; in other words, they look exactly the way Raphael Sanzivs left at the moment he placed the glass over the painting. A conventional canvas painting may have its pictorial surface exposed to a series of events, such as eventually corrections/adjusts after its completion. However, in the case of this painting on glass (Figure 1), the entire pictorial surface never suffered any manipulation due to the glass covering. This demonstrates the great ability of Raphael Sanzivs with the painting technique, once after the last brush stroke the glass is immediately set; and after that, no correction is possible. This explains why there are some distortions on the lineation of some characters' lines. Nevertheless, even with some distortions on the original lines [due to the glass overlay], it is still possible to find on its pictorial surface countless partially hidden Raphael Sanzivs' signatures/initials, of which he used on his artworks. ${ }^{12,13}$ See below:

Through the Buso method, ${ }^{11,14}$ are evinced on the anatomy of the characters of the painting on glass the initial letters of Raphael Sanzivs Vrbinas' name ['RVS', 'RS', 'RV'], such as his signature ['SANZIVS' and 'RAPHAEL'] and the likely number ['13'], probably designating the year in which the work was prepared (1513). Additionally, the initial letters of Raphael Vrbinas' name ['RA'] can also be found on St. Joseph's vestment (Figures 2, 3 and 4).

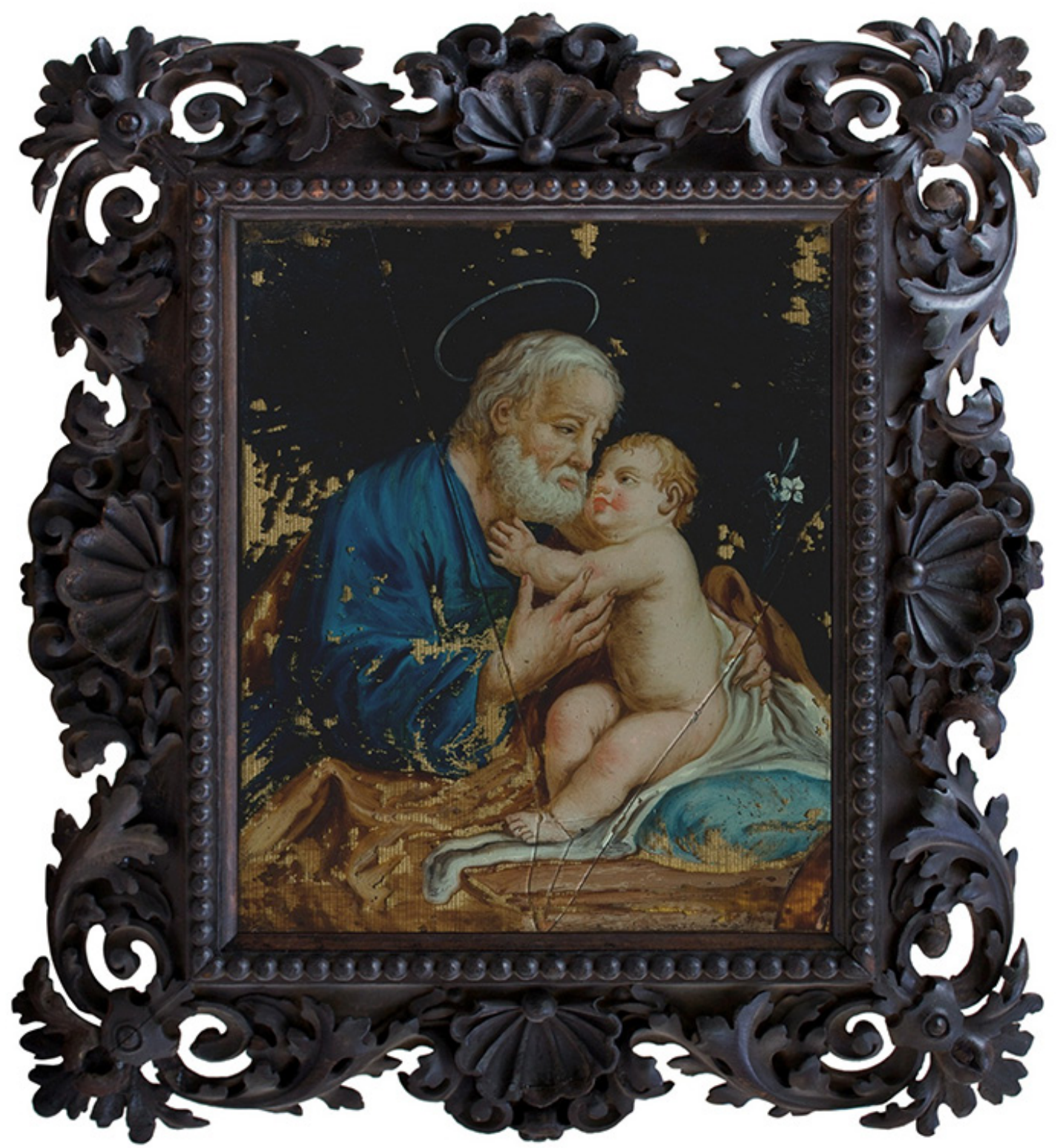

Figure 1. Painting on glass (St. Joseph and the Infant Jesus, 1513) by Raphael Sanzivs Vrbinas [oil paint or tempera; $30 \mathrm{~cm} \times 25 \mathrm{~cm}$; belonging to a private collection]. 

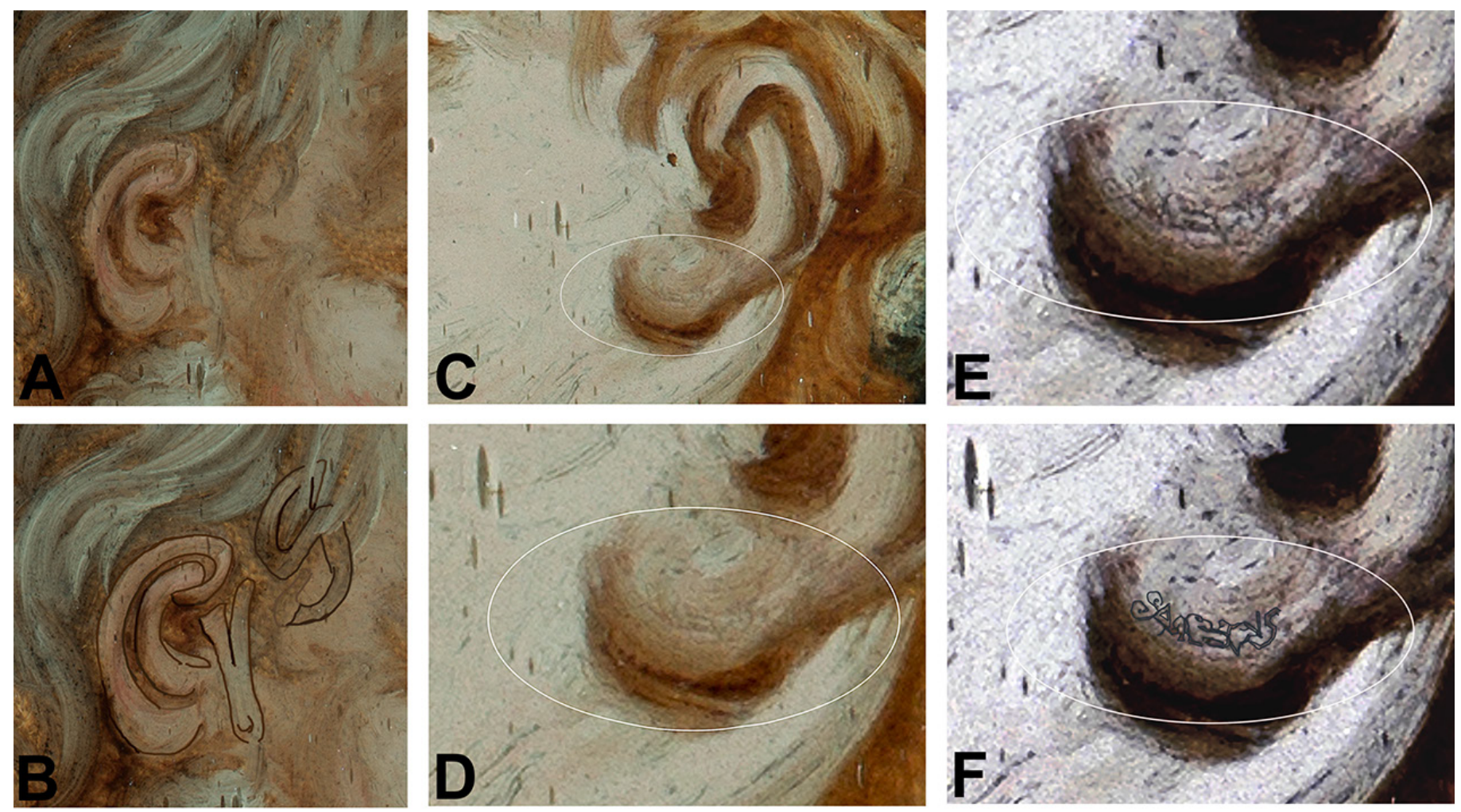

Figure 2. (A) Detail in St. Joseph's right ear and hair on the painting on glass, presenting the outline/shape of the letters 'RVS' (B) from Raphael Sanzivs Vrbinas' name [Buso method]. (C) Additionally, it is possible to observe on Infant Jesus' left ear lobe traces of the signature Sanzivs [white circle], subtly inscribed between the lines that compose the painting strokes (D). (E) Note that with the color change and the magnification of the Infant Jesus' left ear lobe, the signature Sanzivs becomes even more evident [white circle] by the letter lineation (F) [Buso method] [Magnification $300 \%$ ]. All images were obtained through a high-resolution photographic camera [Hasselblad], and the image coloring was purified until $90-99 \%$ by a photolithography specialist.
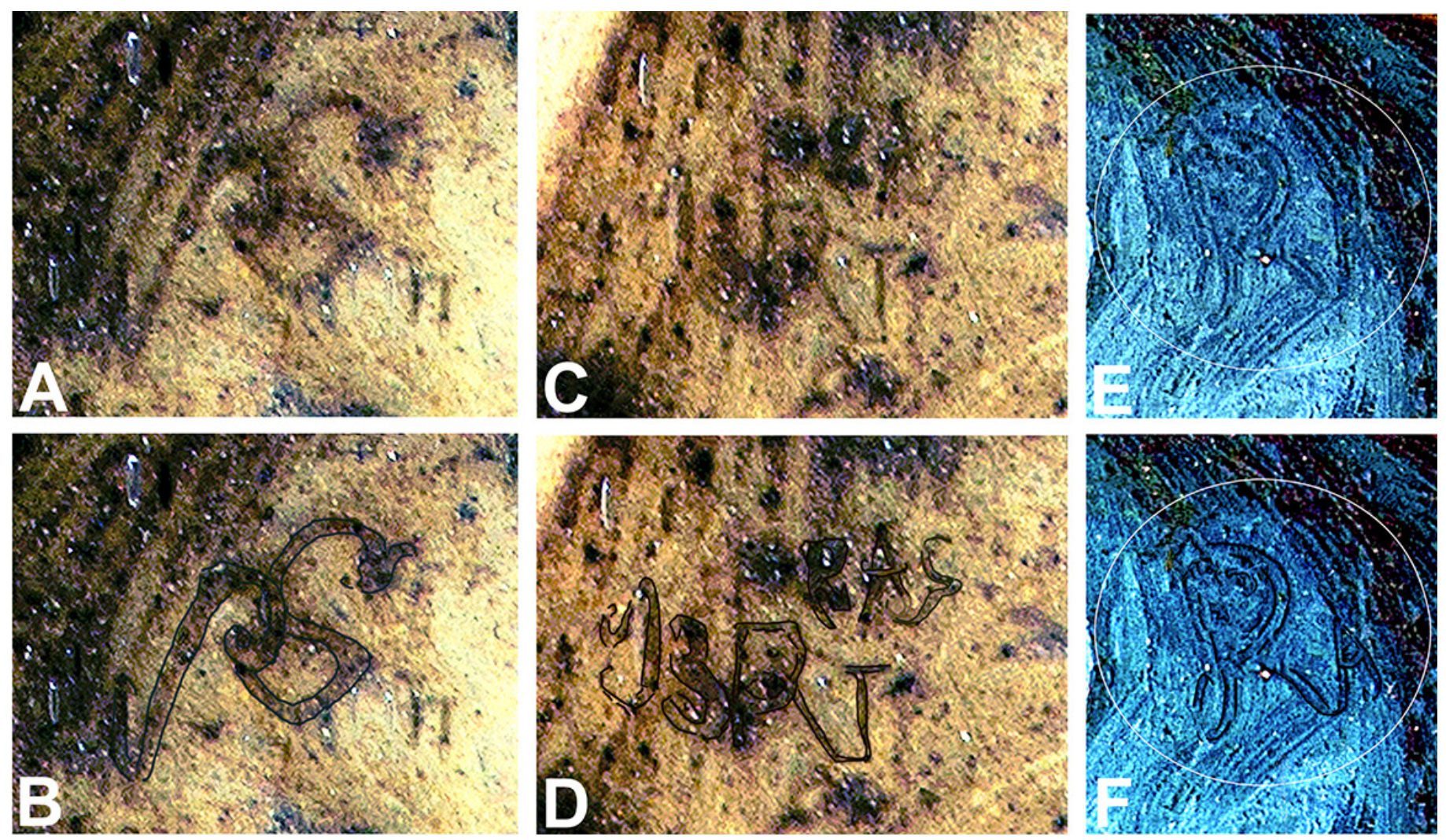

Figure 3. (A) Detail on Infant Jesus' left armpit on the painting on glass where it is possible to observe the traces of the letters 'RS' from the name of Raphael Sanzivs, which are evident after their lineation (B) [Buso method]. (C) Note that with the color change and the magnification of the image, immediately below the letters 'RS' on Infant Jesus' left armpit, traces of numbers and letters ['RAS' and '13RV'] appear, which are evident after their lineation (D) [Buso method]. (E) Furthermore, on the right sleeve of St. Joseph's vestment it is possible to observe the traces of the letters 'RA' [white circle], which are evident after their lineation (F) [Buso method] [Magnification 300\%]. All images were obtained through a high-resolution photographic camera [Hasselblad], and the image coloring was purified until $90-99 \%$ by a photolithography specialist. 


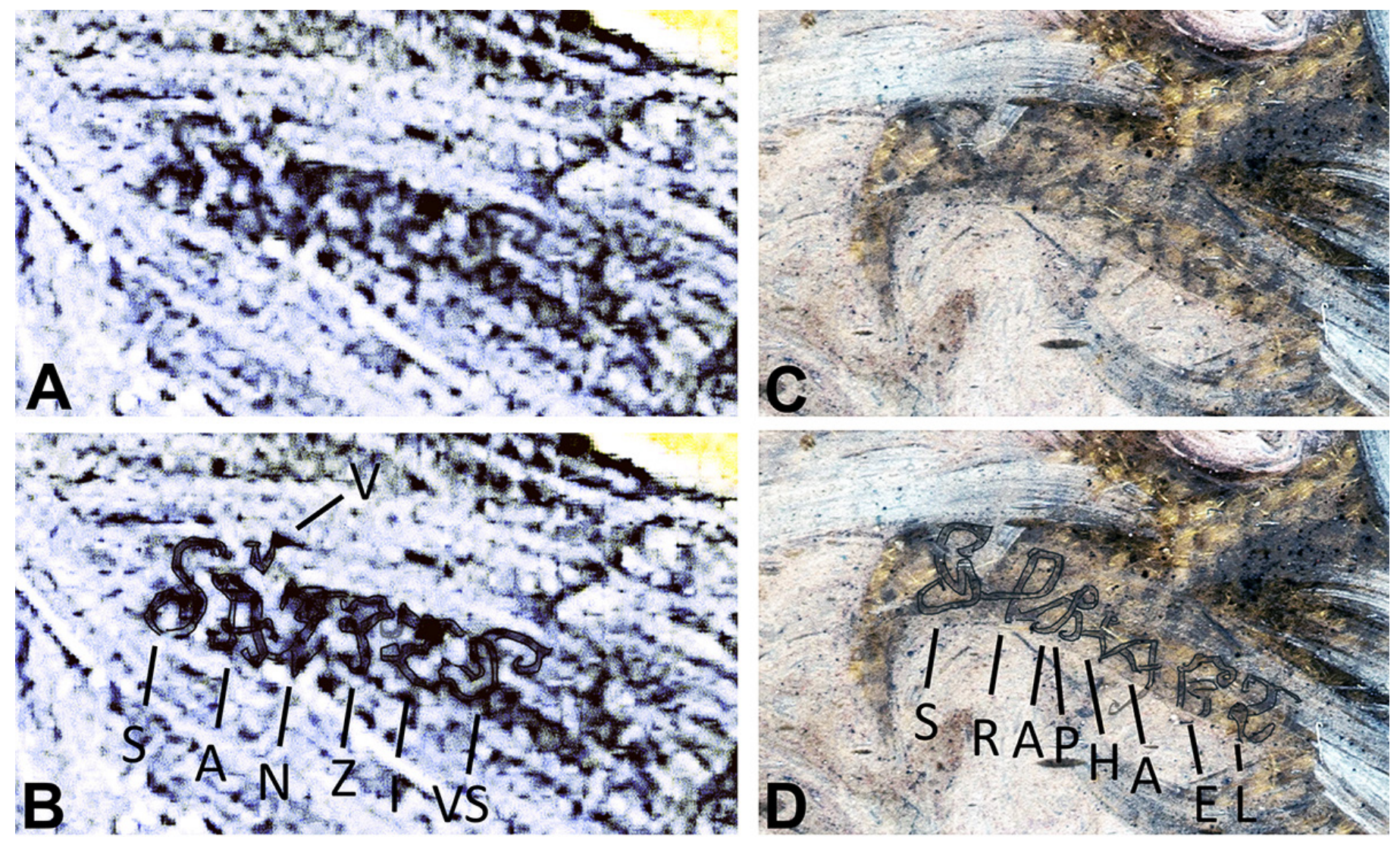

Figure 4. (A) Note that with the color change and the magnification of the mantle of St. Joseph, it is possible to observe signs of the letters 'V SANZIVS' (B). In addition, near the ear of St. Joseph (C), the spelling 'S RAPHAEL' (D) is also evident [Buso method] [Magnification 300\%]. All images were obtained through a high-resolution photographic camera [Hasselblad], and the image coloring was purified until $90-99 \%$ by a photolithography specialist.

\section{Historical and iconographic analysis}

Renowned authors ${ }^{4}$ have pointed out that many of the most famous works of art from the Renaissance are replete with hidden ideas and secret codes. This may be due to the fact that at that time; even the most renowned painters were considered mere employees, and often could not express their real intentions when elaborating their works, especially those commissioned by the Catholic Church. There were many restrictions that hampered and limited the artists of that period. Perhaps, the main fact was that the artists, particularly those commissioned by the hierarchy of the Catholic Church, were forbidden to sign their own works. The stated purpose was to ensure artists remained in their places and to protect them from the sin of pride. For this reason, many artists inserted images of their own faces, or even letters alluding to their names within their works. ${ }^{4}$ To do so, many artists, including Raphael Sanzivs, used magnifying glasses/lenses to give more realism to their works and also to make their personal marks undetectable to the naked eye. ${ }^{15}$ Raphael Sanzivs, also included his initials [sometimes in a partially hidden way with the use of magnifying glass/ optical lenses] in several of his works (Figure 5).,12,13,15-18

Classically, the specialized literature ${ }^{4,12,16}$ describe, also, that the reason why Raphael Sanzivs frequently partially hid his signatures/initial letters on the artworks, is the fact that for them being elaborated by the same artist, that had an enormous prestige, they used to arouse the interest of many people; and consequently, sometimes they ended up being stolen. We must keep in mind that a clear and legible signature exposed on the edge of a work of art or maybe behind of it, would easily arouse the interest of thieves. Therefore, the art of hiding the signatures (or initial letters) in different spots on the artworks, and in a very discreet way [through magnifying glass/optical lenses], has become a need. ${ }^{12,15}$ Furthermore, it was obvious that if Raphael Sanzivs hid his signature inside his characters bodies silhouettes the identification could be much more difficult (but not impossible), because depending on the shape and on the spot where it had been done, the letters of his name would easily be mistaken with the anatomy of the represented region/structure itself. In this context, it can also be explained the great interest of Raphael Sanzivs by the studies of the human body. The preparatory card for the Borghese Deposition [anatomical study] itself (Figure 5A) demonstrates that Raphael Sanzivs was very interested in this subject (human anatomy). ${ }^{3}$ Specialized authors ${ }^{2,3}$ describe, also, some specific comments related to Raphael Sanzivs' interest in human anatomy, see below:

When Raphael arrived in Florence in 1504 or 1505, he was immediately presented with an opportunity to compare his own work with two opposing models for understanding artistic anatomy: the more comprehensive, scientific approach of Leonardo and 

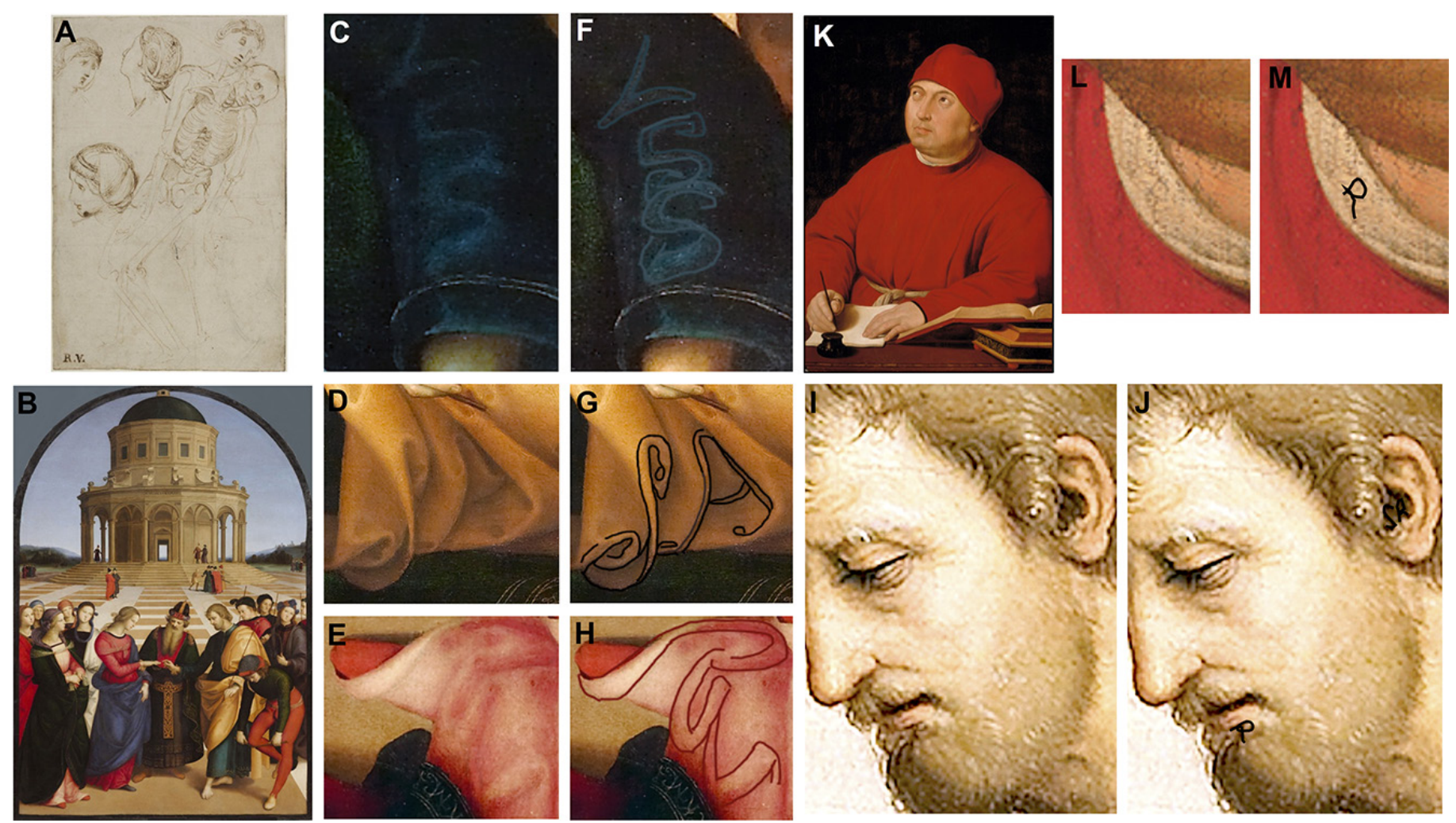

Figure 5. (A) Anatomical study for Borghese Deposition by Raphael Sanzivs Vrbinas in 1506-7. Note the initial letters 'R.V.' of the artist's name at the bottom of the drawing [Pen and brown ink, over black chalk; 30.5 × $20.2 \mathrm{~cm}$; British Museum; London]. (B) The Betrothal of the Virgin elaborated by Raphael Sanzivs Vrbinas in 1504, with emphasis on the tunica that covers St. Joseph's right arm up (C), St. Joseph's vestment (D) and the tunica that covers the woman's on the side of Virgin Mary feet up (E); because it is exactly in these spots that they reveal themselves [Buso method] respectively, the initial letters from Raphael Sanzivs Vrbinas' name, 'VSS' ( $F$ ), 'SA' (G) and 'RV' (H). In addition, in the mouth and ear (I) of St. Joseph, the letters ' $\mathrm{R}$ ' and 'SR' (J) are also highlighted [Buso method]. [Oil on panel; $174 \mathrm{x} 121 \mathrm{~cm}$; Pinacoteca di Brera; Milan]. (K) Portrait of Tommaso Inghirami (1470-1516) painted by Raphael Sanzivs Vrbinas in 1516, with emphasis on the white collar of Tommaso's tunica (L) for revealing [Buso method] the 'R' letter (M) from Raphael's name [Oil on panel; 62.2 x 89.7 cm; Isabella Stewart Gardner Museum; Boston].

the more strictly artistic, anthropocentric one of Michelangelo and, before him, Pollaiuolo. Indeed, Vasari's description of Raphael's anatomical studies could as easily be applied to Michelangelo: He then devoted himself to studying the nude and to compare the muscles of anatomical subjects and of flayed human bodies with those of the living...; and going on to observe in what way they acquire the softness of flesh in the proper places, and how certain graceful flexures are produced by changing the point of view, and also the effect of inflating, lowering, or raising either a limb or the whole person, ... he became excellent in all the points that are looked for in a painter of eminence.

Therefore, Raphael's concept of anatomy was personal and highly sophisticated. He applied research on anatomy and the equilibrium of the body in an original way to his studies for numerous paintings/ works. This subtle play of equilibrium, of static release and dynamic action, was a key component of the invention of harmonic figure composition that was one of the principal features of Raphael's art. ${ }^{3}$ Besides, there are further strong indications that Raphael Sanzivs may have produced this painting on glass in 1513 , influenced by the religious events of the time, as well as his strong bond with noble representatives of the Oratories/Confraternities of St. Joseph, located in Urbino.

Specialists ${ }^{19,20}$ point out that St. Joseph, as from
Pope Sixtus IV in 1479, and later, with Isidoro Isolano's Summa de Donis Sancti Josephi [composed between 1514-1521], came to have considerable importance throughout Italy, especially in Renaissance art. It is even described ${ }^{20-22}$ that both Raphael Sanzivs and his teacher, Pietro Perugino, actively participated in a confraternity that exalted St. Joseph's image. And in fact, this can be demonstrated by the large number of paintings that refer to the Holy Family/St. Joseph that Raphael produced throughout his career. ${ }^{21,22}$

Therefore, the cultural context of the period and the iconography of the painting on glass reveal a subject (St. Joseph) that really influenced and inspired the artist. In this context, this artwork genuinely presents itself, because it evinces the renowned painter Raphael Sanzivs as a real anatomist-artist. This is especially due to the fact that even with all difficulties of the glass painting technique, his signatures were still perceptible in this artwork, which may be the only one [in glass] remaining from the artist related to this theme that inspired him so much. Obviously, this was only possible because Raphael Sanzivs, besides knowing the painting techniques through magnifying glass/optical lenses, ${ }^{15,16}$ also knew the details of the human body. ${ }^{2,3}$ Leon Batista Alberti (1404-1472), who was a maximum example of a renaissancist man, wrote the following: the artist in his social context can't be a mere craftsman, but an intellectual versed 
in all disciplines/subjects and fields, including the human anatomy. ${ }^{4}$ In this regard, it is notorious that the painting on glass really shows the artist's abilities, since he chose specific anatomical regions in his characters, where his signatures could be inserted without being completely hidden by the overlaying glass.

Finally, we can still emphasize that the informations exposed in this manuscript stand out not only for evincing Raphael Sanzivs' expertise and interests [painting and anatomy], but also because they can be used as a basis for future studies that aim the proof of
Raphael Sanzivs' authorship in eventual artworks that may haven't yet been attributed to the referred artist. In addition, the present manuscript shall be important for professionals in the medical-artistic field and those who keep some interest in the history of anatomy, which is undoubtedly an important discipline for the practice of medicine.

"Look within. Let neither the peculiar quality of anything nor its value escape thee."

Marcus Aurelius Antonius (121-180), Meditations

\section{References}

1. Darlington A. The Teaching of Anatomy and the Royal Academy of Arts 1768-1782. Journal of Art and Design Education 1986; 5:263-271. 2. Ames-Lewis F, Joannides P. Reactions to the Master: Michelangelo's Effect on Art and Artists in the Sixteenth Century. Burlington: Ashgate Publishing; 2003.

3. Laurenza D. Art and Anatomy in Renaissance Italy: Images from a Scientific Revolution. New York: Metropolitan Museum of Art; 2012.

4. Blech B, Doliner R. The Sistine Secrets: Michelangelo`s Forbidden Messages in the Heart of the Vatican. New York: HarperCollins Publishers; 2008.

5. Santos IP, Rosa JPC, Ellwanger JH, Molz P, Rosa HT, Campos D. Michelangelo's art on the Sistine Chapel ceiling: sacred representation or anatomy lessons? J Morphol Sci 2013; 30:1-6.

6. De Campos D, Malysz T, Bonatto-Costa JA, et al. The hidden symbols of the female anatomy in Michelangelo Buonarroti's ceiling in the Sistine Chapel. Clin Anat 2016; 29:911-916.

7. De Campos D, Oxley Da Rocha A, De Oliveira Lemos R, et al. Pagan symbols associated with the female anatomy in the Medici Chapel by Michelangelo Buonarroti. Clin Anat 2017; 30:572-577.

8. Gurunluoglu R, Gurunluoglu A, Williams SA, Cavdar S. The history and illustration of anatomy in the Middle Ages. J Med Biogr 2013; 21:219-229.

9. Lazzeri D, Al-Mousawi A, Nicoli F. Sandro Botticelli's Madonna of the Pomegranate: the hidden cardiac anatomy. Interact Cardiovasc Thorac Surg 2019; 28:619-621.

10. Campos D, Buso L, Bagatini PB, Prass DI, Xavier LL. The Golden Ratio and Michelangelo's Influence in Gaspar Becerra`s Flayed Man. J Morphol Sci 2021; 38:57-61.

11. Buso L. Firme e date celate nei dipinti da Giotto ai tempi nostri.
Castelfranco Veneto: Duck; 2011.

12. Farabulini D. Sopra una Madonna di Raffaello d'Urbino a lui negata dal passavant e da altri storici: ragionamento critico-estetico in continuazione de'nuovi studi su Raffaello. Rome: Tipografia della pace; 1875.

13. Lampe L. Signatures et monogrammes des peintres de toutes les écoles et époques, Volume 2. Bruxelles: Ed. Collections Livres; 1999. 14. Buso L, Rodrigues DC, de Campos D. The handedness of Leonardo da Vinci (1452-1519) analyzed from his hidden signature in the Mona Lisa. J Med Biogr 2021; doi: 10.1177/0967772020974581.

15. Carrell JL. Mirror images: artist David Hockney shocks the art world with his claim that grand masters from van Eyck to Ingres secretly used lenses in their work. Smithsonian 2002; 32:76-82.

16. Vasari G. The Lives of the Artists. Oxford: Oxford University Press Inc; 1991.

17. Pagden SF, Zancan MA. Rafael. Madrid: Ediciones Akal; 1993.

18. Müntz E. Raphael - Volume 1. New York: Parkstone Press International; 2018.

19. Ainsworth MW, Christiansen K. From Van Eyck to Bruegel: Early Netherlandish Painting in The Metropolitan Museum of Art. New York: The Metropolitan Museum of Art - Harry N. Abrams Inc; 1999. 20. Wilson CC. St. Joseph in Italian Renaissance Society and Art: New Directions and Interpretations. Philadelphia: Saint Joseph's University Press; 2001.

21. Hall MB. The Cambridge Companion to Raphael. New York: Cambridge University Press; 2005.

22. Hope JE. Transformations of the image of St joseph in early modern art. Birmingham: Birmingham City University; 2011.
Received: April 3, 2021

Accepted: May 10, 2021
Corresponding author

Deivis de Campos

E-mail: dcampos@ufcspa.edu.br 